\title{
New Correlations for Coal and Biomass Pyrolysis Performances with Coal-Biomass Type Number and Temperature
}

\author{
Yazid Bindar \\ Research Group on Energy and Processing Systems in Chemical Engineering \\ Department of Chemical Engineering, Faculty of Industrial Technology \\ Institut Teknologi Bandung, Jalan Ganesa No.10 Bandung 40132, Indonesia \\ Email: yazid@fti.itb.ac.id
}

\begin{abstract}
The pyrolysis of coal and biomass is generally reported as the mass yield of released chemicals at various temperatures, pressures, heating rates and coal or biomass type. In this work, a new coal-biomass type number, $N_{C T}$, is introduced. This number is constructed from the mass fractions of carbon, hydrogen, and oxygen in the ultimate analysis. This number is unique for each coal or biomass type. For 179 different species of coal and biomass from the literature, the volatile matter mass yield can be expressed by the second order polynomial function $\ln \left(N_{C T}\right)$. This unique correlation allows the effects of the temperature and heating rate on the volatile yield $Y_{V Y}$ for coal and biomass to be empirically correlated as well. The correlation for the mass fraction of each chemical component in the released volatile matter correlation is obtained from the $Y_{V Y}$ correlation. The weight factor for some of the components is constant for the variation of $N_{C T}$, but not for others. The resulted volatile matter and yield correlations are limited to atmospheric pressure, very small particles (less than $0.212 \mathrm{~mm}$ ) and interpreted for wire-mesh pyrolysis reactor conditions and a nitrogen gas environment.
\end{abstract}

Keywords: Coal-biomass type number; emperical pyrolysis correlations; pyrolysis performance; volatile components; volatile proximate matter; volatile yield.

\section{$1 \quad$ Introduction}

Coal or biomass pyrolysis plays a very important role in the combustion and gasification processes. Pyrolysis is classified as a chemical decomposition phenomenon of solid fuels. It produces volatile matter in the form of light gases and tars. This process requires the heat to decompose the coal or biomass into volatile products and char. The light gases and tars are oxidized by the available oxygen to release gaseous products and heat. The heat must be released continuously at least at a minimum rate to undergo the interlinked processes between pyrolysis, volatile combustion and char oxidation.

Received August $3^{\text {rd }} 2012$, Revised July $4^{\text {th }} 2013$, Accepted for publication September $20^{\text {th }} 2013$.

Copyright $\odot 2013$ Published by ITB Journal Publisher, ISSN: 2337-5779, DOI: 10.5614/j.eng.technol.sci.2013.45.3.5 
Many parameters affect coal or biomass pyrolysis during the combustion or gasification process. These parameters are: (i) temperature, (ii) pressure, (iii) heating rate, (iv) coal or biomass type, (v) coal or biomass particle size, (vi) combustion or gasification process method - whether fixed bed, fluidized bed, pulverized coal or entrained bed, and (vii) pyrolysis environment with or without oxygen atmosphere. The effect of particle size can be excluded if the coal or biomass particle size is very small. The process method makes no difference if the pyrolysis is conducted in a standard wire-mesh reactor (WMR). Pyrolysis without oxygen environment is commonly conducted in a nitrogen (N2) atmosphere. The majority of the pyrolysis data used in this study were obtained for an $\mathrm{N} 2$ environment.

Different types of coal exhibit different pyrolysis performances. Low-rank coals, such as lignites, release more volatile matter than high-rank coals. The chemical components and composition of the volatile product most likely differ from one coal or biomass type to another. To quantify the effect of the coal or biomass type, a numerical coal type number is required.

Carbon content as mass fraction $\left(\% Y_{C}\right)$ is a common coal type number that has been used by many authors, such as Niksa, et al. [1], Mill [2], and Genetti [3]. The light gas and tar yields are the common indicators for expressing how the pyrolysis behaves. However, using carbon content as coal type number does not produce a consistent result.

There are two scientific tools for classifying coals that are generally used: the Seyler coal chart and the van Krevelen diagram. The Seyler coal chart relates the chemical component values of carbon $(\mathrm{C})$ and hydrogen $(\mathrm{H})$ and oxygen $(\mathrm{O})$ to the various coal properties. The van Krevelen diagram relates two sets of atomic mass ratios, $Y_{H} / Y_{C}$ and $Y_{O} / Y_{C}$, to the various coal properties. Unfortunately, the $Y_{H} / Y_{C}$ and $Y_{O} / Y_{C}$ ratios are not unique for each type of coal or biomass.

Basically, the general classification of coal or biomass types is indicated by the ultimate analysis that quantifies their elemental composition. The proximate analysis provides information about the mass fraction of volatile matter (VM), fixed carbon (FC), moisture (M) and ash (A). Because the proximate analysis is conducted using a standard process, the results cannot be translated directly to configure the pyrolysis process if the process conditions are not exactly the same as the standard conditions.

The major elements that form coals and biomass are $\mathrm{C}, \mathrm{H}, \mathrm{O}$, nitrogen $(\mathrm{N})$ and sulfur (S). The chemical structure of a coal or biomass is very complex. Various models of coal structures have been constructed by authors such as Schlosberg 
[4] and Solomon, et al. [5]. In fact, many chemical structures can be constructed for the same coal. Currently, it appears that the exact chemical structure has not been uniquely defined for each coal or biomass. In that case, the elements present in the coal are the most suitable features to identify the coal or biomass type.

A new coal or biomass type number is required that is unique for each type of coal or biomass. The coal or biomass type number is formed by two atomic mass ratios, $\mathrm{Y}_{\mathrm{C}} / \mathrm{Y}_{\mathrm{H}}$ and $\mathrm{Y}_{\mathrm{C}} / \mathrm{Y}_{\mathrm{O}}$. This number is obtained by multiplication of the two mass ratios. Each coal or biomass should have a single value for this number. The proposed coal or biomass type number is used to characterize the coal or biomass pyrolysis performance in order to form empirical correlations.

The objective of this work is to develop such a new coal type number in order to cover a wide range of coals, including biomass. The proposed empirical models are presented in several correlations of new unique parameters. Hopefully, these correlations can be used for practical purposes to predict any pyrolysis parameter from the coal type number and other operational variables. The proposed correlations work at atmospheric pressure, for very small coal or biomass particles (less than $0.212 \mathrm{~mm}$ diameter) and wire-mesh pyrolysis reactor conditions with an $\mathrm{N}_{2}$ gas environment.

The ultimate and proximate analysis results and other available experimental data for a wide spectrum of coal and biomass types were found in the literature. The results show that the proposed coal or biomass type number is a unique and independent variable.

Having a unique correlation of the mass fraction of volatile matter to the coal or biomass type number $N_{C T}$ allows the effects of temperature and heating rate to be quantified. This results in an empirical correlation for the volatile yield $Y_{V Y}$. The mass fraction correlation for any chemical component in the released volatile matter can then be formulated from the obtained empirical correlation.

\section{Formulation}

The coal quality, described as energy content, is mainly determined by the elements $\mathrm{C}, \mathrm{H}$ and $\mathrm{O}$. The mass fractions of these elements are reported as an ultimate analysis. Anthracite coal has the highest energy content of all coals. This feature correlates directly to higher $\mathrm{C}$, lower $\mathrm{H}$ and lower $\mathrm{O}$ contents. The coal quality is reduced when the coal has lower $\mathrm{C}$, higher $\mathrm{H}$ and higher $\mathrm{O}$ contents. The lowest ranking coal is lignite, which has higher $\mathrm{O}$, lower $\mathrm{C}$, and higher $\mathrm{H}$ contents. For example, from biomass to anthracite coals, the $\mathrm{C}$ content 
ranges from 44 to $95 \%$, the $\mathrm{H}$ content decreases from 7.5 to $1 \%$, and the $\mathrm{O}$ content decreases from 50 to $1 \%$.

The pyrolysis performance depends on the coal or biomass type and several operational parameters. These operational parameters are: pressure, temperature and heating rate (Niksa, et al. [1]). The performance is quantified by the pyrolysis mass rate, yields and light gas and tar composition.

As well as by the ultimate analysis, coal or biomass qualities are described by volatile matter, fixed carbon, ash and moisture contents. These contents are reported in the proximate analysis. The volatile matter mass fraction of volatile matter $Y_{V M}$ was measured using the standard measurement method described in ASTM 3175-07. This method is considered a pyrolysis process at a moderate temperature level, slow heating rate and long exposure time. The particle size is smaller than $212 \mu \mathrm{m}$. The material is heated to $900^{\circ} \mathrm{C}$ for 7 minutes. During the first minute, the heating rate is increased to $13^{\circ} \mathrm{C} / \mathrm{s}$, and for the second minute, the heating rate is set to $2.5^{\circ} \mathrm{C} / \mathrm{s}$. After the second minute, the heating rate is maintained at $0.1^{\circ} \mathrm{C} / \mathrm{s}$.

By referring to the method above, the volatile matter content in the proximate analysis is actually considered a result of the pyrolysis process under standard conditions. Therefore, the volatile matter contents from the proximate analysis can be correlated to the coal or biomass type number.

Mass fraction $Y_{C}$ increases from biomass to anthracite coal. Mass fraction $Y_{O}$ behaves in the opposite way to the $\mathrm{C}$ element mentioned above. Mass fraction $Y_{C}$ is divided by mass fraction $Y_{O}$ to define $N_{C / O}$ as

$$
N_{C / O}=\frac{Y_{C}}{Y_{O}}
$$

This value consistently increases from biomass to anthracites.

In the same way, mass fraction $Y_{H}$ evolves from high to low values from biomass to anthracites. When $Y_{C}$ is divided by $Y_{H}, N_{C / H}$ is defined as

$$
N_{C / H}=\frac{Y_{C}}{Y_{H}}
$$

The value of this parameter also increases from biomass to anthracites.

These two parameters are multiplied together to give a coal or biomass type number $N_{C T}$ that is defined as 


$$
N_{C T}=N_{C / O} N_{C / H}=\frac{Y_{C}}{Y_{O}} \frac{Y_{C}}{Y_{H}}
$$

The value of this coal or biomass type number also consistently increases from biomass to anthracites. Moreover, this value should be unique for each coal or biomass type. This parameter becomes a single parameter that covers the mass fractions of $\mathrm{C}, \mathrm{H}$ and $\mathrm{O}$ as major elements of biomass and coals.

The mass fraction of volatile matter $Y_{V M}$ can be correlated to the coal or biomass type number $N_{C T}$. The general correlation of $Y_{V M}$ to $N_{C T}$ is stated as

$$
Y_{V M}=f_{1}\left(N_{C T}\right)
$$

The value of $N_{C T}$ for anthracite is very high because of its higher $Y_{C}$ and lower $Y_{O}$ and $Y_{H}$. The top limit of $N_{C T}$ is infinite. A very high $N_{C T}$ gives a very low value for $Y_{V M}$. For biomass, the $N_{C T}$ value should be very low due to the low $Y_{C}$ values and high $Y_{O}$ and $Y_{H}$ values. This produces a very high $Y_{V M}$ that approaches to one. The boundaries of the correlation of Eq. (4) are defined as

$$
\begin{array}{lll}
\text { Anthracite, } & N_{C T} \rightarrow \infty, & Y_{V M} \rightarrow 0 \\
\text { Biomass }, & N_{C T} \rightarrow 0, & Y_{V M} \rightarrow 1
\end{array}
$$

When these boundaries are applied, the most suitable correlation is an exponential function of $N_{C T}$ that is expressed as

$$
\begin{array}{ll}
Y_{V M}=\exp \left[-f_{2}\left(N_{C T}\right)\right] & \text { where } f_{2}\left(N_{C T}\right)>0 \\
\% Y_{V M}=100 Y_{V M}=100 & \exp \left[-f_{2}\left(N_{C T}\right)\right]
\end{array}
$$

The function $f\left(N_{C T}\right)$ is proposed as a polynomial function of $N_{C T}$

$$
f_{2}\left(N_{C T}\right)=a+b \ln \left(N_{C T}\right)+c\left(\ln N_{C T}\right)^{2}+\mathrm{d}\left(\ln _{\mathrm{CT}}\right)^{3}
$$

The operational conditions of coal and biomass combustion or gasification differ from the proximate analysis conditions. The heating rate $\beta$ and pressure $P$ can be higher than the proximate analysis conditions. Niksa [1], Mill [2], Genetti [3], and $\mathrm{Xu}$ and Tomita [6] have investigated the pyrolysis behavior of different coals under different conditions. The measured pyrolysis variables were light gas mass fraction, tar yield, total volatiles, and volatile enhancement. The effects of the different coal types on these variables were plotted against $\% Y_{C}$. Because $\% Y_{C}$ is not unique for each coal, it is difficult to draw a consistent trend for the effect of the coal type. 
Pressure affects the pyrolysis performances. High-pressure pyrolysis releases less volatile compounds than low-pressure pyrolysis. Niksa [1], Lee, et al. [7], Fatemi [8], and Yeasmin, et al. [9]. Zeng [10] have shown that the tar reduction and total volatile yield are more significant for bituminous coals, but less significant for lignites. An interesting hypothesis from Zeng's work is that the effect of pressure on the total volatile yield is more significant at higher temperatures. Tamhankar, et al. [11] have stated a surprising finding in which the volatile yield increased with pressure at temperatures between $800^{\circ} \mathrm{C}$ and $900^{\circ} \mathrm{C}$. This implies that the effect of pressure is more complicated than the effects of the other parameters. This needs to be elaborated and discussed more deeply in another study. The present work does not cover the effect of pressure.

The proposed coal type number is preferably used in describing how the pyrolysis variables behave in relation to the coal type. The mass yield of a chemical component resulted by the pyrolysis process is stated as $Y_{i}$. The correlation between $Y_{i}$ and the coal type number and other operational conditions is defined as

$$
Y_{i}=f_{3}\left(N_{C T}, \beta, T\right)
$$

It is our intention to construct the correlation of Eq. (9) using the experimental data of pyrolysis performances available in the literature.

\section{Coal and Biomass Databank}

To formulate the correlations between pyrolysis behavior and coal-biomass type number, the proximate and ultimate data from a wide range of types and origins were used. These coal and biomass data were gathered from different sources in the literature. In total, 179 coal data sets were used for this study; 6 Australian coals provided by Mill [2], 29 USA coals published in Genetti [3], and 21 coals reported by Xu and Tomita [6]. The rest were coals found in references [12-16] and originated from Canada, China, Japan, Germany, Indonesia, Slovenia, Ukraine, Korea, Vietnam and India.

The different sources of biomass data studied were reported by Parikh, et al. [17]. Some of the biomass was defined as char. In total, 37 biomass datasets were available.

All the 179 coal and biomass data sets were ranked from the lowest to the highest carbon, oxygen and hydrogen contents. These data cover the ultimate and proximate analysis data. The ultimate data are presented in terms of the mass fractions of $\mathrm{C}, \mathrm{H}, \mathrm{O}, \mathrm{N}$ and $\mathrm{S}$. 
The proximate data are reported as percentage of mass fraction of volatile matter and fixed carbon. The ash is quantified by the mass ratio between the ash and the coal by excluding the water and ash contents

Some data sets in the literature report higher heating values, while others do not. Therefore, the high heating values $\left(H_{H V}\right)$ used here were calculated from the correlation given by Parikh, et al. [17].

\section{$4 \quad$ Results and Discussion}

\subsection{Volatile Matter Correlation}

The coal quality is commonly shown as the $\mathrm{H} / \mathrm{C}$ mass ratio versus the $\mathrm{O} / \mathrm{C}$ mass ratio, as is referred to in the van Kravelen chart [18]. This chart is meant only for mapping coals in terms of their chemical element contents. The van Krevelen diagram for the 179 coal and biomass data sets used in this study are shown in Figure 1. Even though they correlate positively to each other, there is no need to construct a mathematical correlation between them in Figure 1. Besides that, using one of the aforementioned ratios as a coal or biomass type number does not cover all major chemical elements that form the coal or biomass.

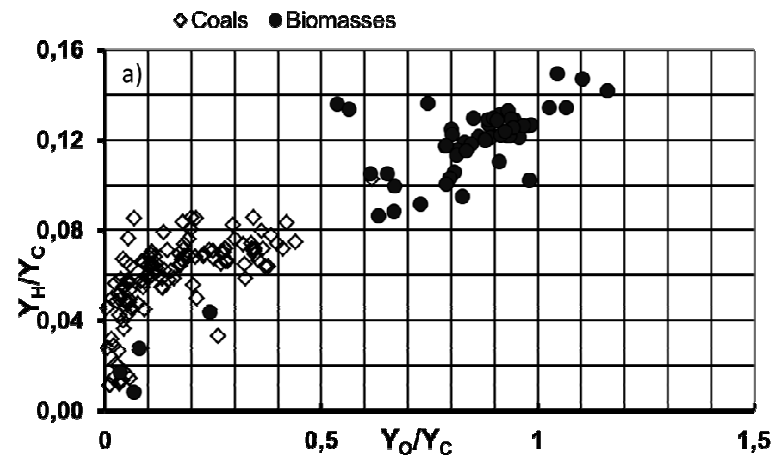

Figure 1 Van Krevelen diagram for coals and biomass in the databank.

Volatile matter is released during the proximate analysis and is reported as mass fraction percentage $\% Y_{V M}$. Because the proximate analysis is conducted under certain conditions, the volatile matter mass cannot be considered as the contents of the volatile matter in the coal or biomass. Because the values of $\% Y_{V M}$ from the literature were obtained under standard conditions, the plot of $\% Y_{V M}$ with the various coal or biomass type numbers accurately characterizes the coal or biomass pyrolysis performance. First, $\% Y_{V M}$ is plotted against $\% Y_{C}$ of coal or 
biomass, as was done by most authors, such as Niksa, et al. [1], Genetti [3] and $\mathrm{Xu}$ and Tomita [6]. The plot for all coal and biomass types is shown in Figure 2.

When $\% Y_{C}$ is used as a coal type parameter, the correlation between the other major elements $(\mathrm{H}$ and $\mathrm{O})$ and $\% Y_{C}$ should be very clear and strong. However, in fact, the correlation between $\% Y_{H}$ and $\% Y_{C}$ is found to be scattered and the correlation between $\% Y_{O}$ and $\% Y_{C}$ is very scattered and weak. For this reason, $\% Y_{C}$ does not provide a unique coal type parameter.

Figure 2 shows a significant and strong effect of $\% Y_{C}$ on volatile matter release $\% Y_{V M}$. One may construct an empirical correlation between these two parameters. Since $\% Y_{C}$ alone cannot characterize coal or biomass types in the form of a unique parameter, it is irrelevant to build an empirical equation to describe this relationship. Moreover, it is difficult to justify the use of only the carbon content as a coal or biomass type number, because it does not consider the oxygen and hydrogen contents. Both the oxygen and the hydrogen content have a significant impact on the pyrolysis performance of coal and biomass.

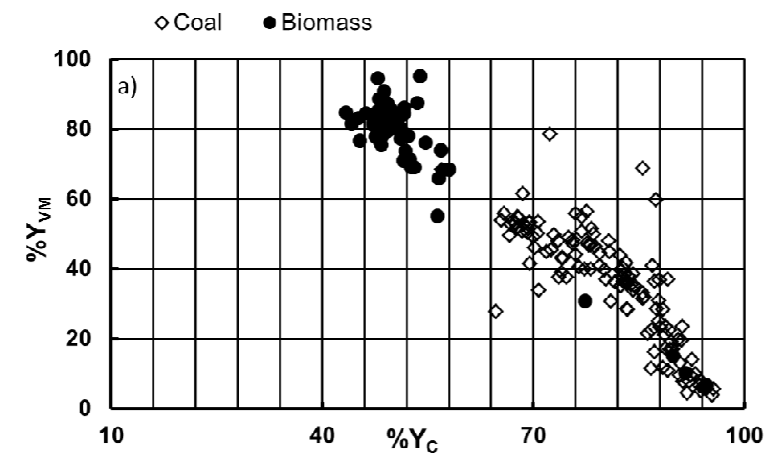

Figure 2 Correlation of the mass fraction of released volatile matter in the proximate analysis with the carbon content of the coals and biomass from the databank.

Because $\% Y_{C}$ alone as coal type number is not suitable, based on the reasons provided above, a new coal type number, $N_{C T}$, Eq. (3), is proposed. A plot by symbols of $\% Y_{V M}$ from the available coal and biomass data compared with this new parameter is presented in Figure 3. A high $N_{C T}$ number relates to the high carbon content of the coal or biomass. Notably, this plot exhibits a correlation of a continuous line from small to large $N_{C T}$ numbers, i.e. from biomass to anthracite coal. This finding is different from that in Figure 2, in which one correlation behavior for all values of $\% Y_{C}$ is not well justified. The correlation 
at higher $N_{C T}$ or higher $\% Y_{C}$ numbers continuously becomes flatter than that of the lower $\% Y_{C}$ coal type numbers.

The $N_{C T}$ parameter uses all three major chemical elements of coal and biomass, carbon (C), hydrogen $(\mathrm{H})$, and oxygen $(\mathrm{O})$. The value of $N_{C T}$ is unique for each coal or biomass type. The $N_{C T}$ number is sufficient to numerically represent each coal or biomass type.

One might argue that $N_{C T}$ does not cover the sulfur (S) and nitrogen (2) contents. However, because the sulfur and nitrogen contents are usually small, the $N_{C T}$ number defined in Eq. (3) is specific enough to generate a unique value for each type of coal or biomass. In fact, the contents of $\mathrm{S}$ and $\mathrm{N}$ scatter against $N_{C T}$.

The model for the $\% Y_{V M}$ correlation with $N_{C T}$ developed here is stated by Eqs. (6)-(8). This model is fitted to the $\% Y_{V M}$ data for the 179 coal and biomass types. The fitted model equation is obtained as follows:

$$
\begin{aligned}
& \% Y_{V M}=100 Y_{V M}=100 \exp \left[f_{2}\left(N_{C T}\right)\right] \\
& f_{2}\left(N_{C T}\right)=0.031-0.029 \ln \left(N_{C T}\right)-0.038\left(\ln N_{C T}\right)^{2}
\end{aligned}
$$

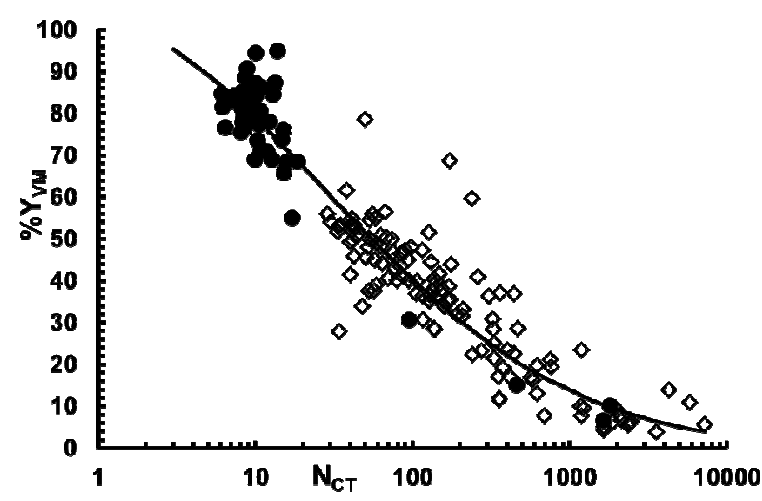

Figure 3 Fitted correlation $\%$ mass fraction of released volatile matter $\% Y_{V M}$ in the proximate analysis for new coal type number $N_{C T}$ from Eqs. (10) and (11) for coal and biomass types from the databank.

The best fitted correlation is at $\mathrm{R}^{2}=0.884$. In Figure 3 , this fitted model is plotted against and compared with the 179 coal and biomass data sets, producing a continuous line. Using the fitted model, the deviation of the predicted $\% Y_{V M}$ from the data is approximately $15 \%$. Knowing $N_{C T}$ only from known values for $\% Y_{C}, \% Y_{H}$ and $Y_{O} \%$, the mass fraction of the released volatile 
matter can be predicted for all types of coals and biomass using Eqs. (10) and (11).

\subsection{Heating Value Correlation}

Under dry conditions, the proximate analysis of a coal or biomass is reported as the mass fraction percentages of volatile matter $\% Y_{V M, d}$, fixed carbon $\% Y_{F C, d}$ and ash $\% Y_{A, d}$. Parikh, et al. [17] developed the high heating value $\left(\mathrm{H}_{\mathrm{HV}}\right)$ model for the entire spectrum of solid carbonaceous materials, such as coals, lignites, biomass, char and residue-derived fuels. That correlation is rewritten as follows:

$$
H_{H V}=84.59 \% Y_{F C, d}+37.30 \% Y_{V M, d}-1.87 \% Y_{A, d} \quad, \quad \mathrm{kCal} / \mathrm{kg}
$$

Knowing the $\% Y_{V M}$ under dry, ash-free conditions from the present correlations expressed by Eqs. (10) and (11), the $\% \mathrm{Y}_{\mathrm{FC}, \mathrm{d}}$ and $\% \mathrm{Y}_{\mathrm{VM}, \mathrm{d}}$ can be calculated from the correlations below:

$$
\begin{aligned}
& \% Y_{V M, d}=\frac{100}{1+\frac{100-\% Y_{V M}}{\% Y_{V M}}+\frac{100}{\% Y_{V M}}\left[\frac{\% Y_{A, d}}{100-\% Y_{A, d}}\right]} \\
& \% Y_{F C, d}=100-\% Y_{V M, d}-\% Y_{A, d}
\end{aligned}
$$

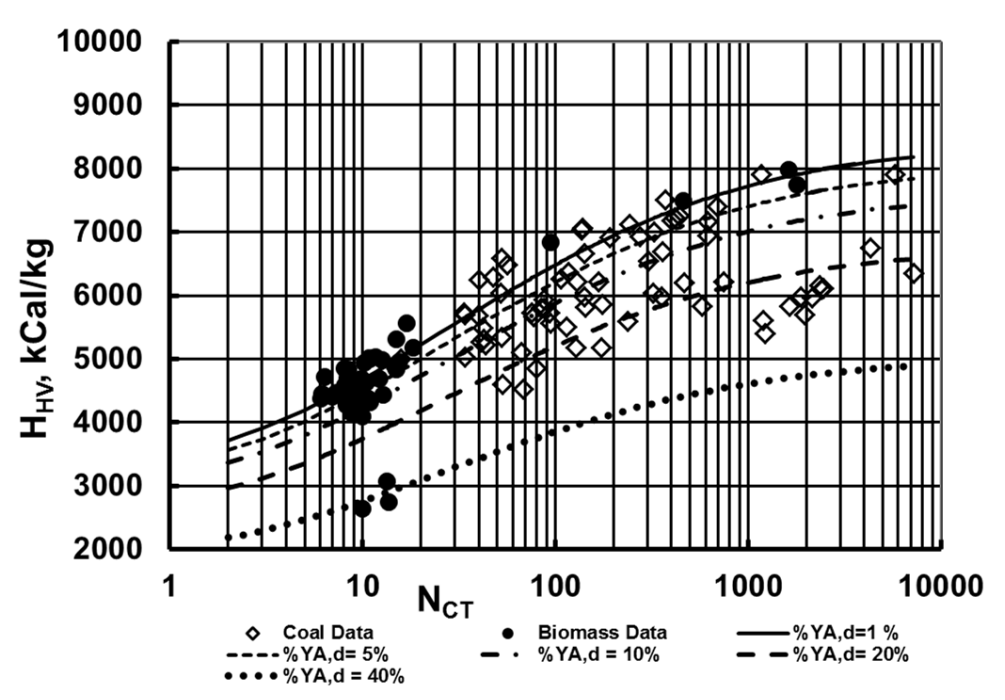

Figure 4 Predicted high heating values of dry coal and biomass correlated to coal type number $N_{C T}$ and ash content $\% Y_{A, d}$. 
The chart of $H_{H V}$ for the entire spectrum of coal and biomass types for different ash contents can be generated from Eqs. (12)-(14). This chart is presented in Figure 4.

Once the ultimate analysis of a coal or biomass is known, the coal type number $N_{C T}$ can be evaluated. With known $N_{C T}, \% Y_{V M}$ is predicted from Eqs. (10) and (11). $\% Y_{V M, d}$ and $\% Y_{F C, d}$ are calculated from Eqs. (13) and (14) for different values of $\% Y_{A, d}$. Subsequently, $H_{H V}$ is predicted using Eq. (12).

Compared to the Dulong equation for $H_{H V}$ prediction, the present correlation predicts $H_{H V}$ within a range of $10 \%$ lower to $10 \%$ higher for the whole biomass and coal range. In fact, the Dulong equation is not considered accurate for prediction of the heating value.

\subsection{Correlations for Pyrolysis Performance}

\subsubsection{Effect of Coal-Biomass Type}

The measurement of pyrolysis performances was comprehensively conducted by $\mathrm{Xu}$ and Tomita [6]. In their experiment, 17 coals were involved. The pyrolysis experiments were set to a temperature of $1037 \mathrm{~K}$, a heating rate of $3000 \mathrm{~K} / \mathrm{s}$, and atmospheric pressure. The pyrolysis performance indicators that were measured were the mass fractions of tar and light gases. The yield data were $\operatorname{tar}\left(Y_{\text {tar }}\right)$, water vapor $\left(Y_{\mathrm{H} 2 \mathrm{O}}\right)$, carbon dioxide $\left(Y_{\mathrm{CO} 2}\right)$, carbon monoxide $\left(Y_{C O}\right)$, methane $\left(Y_{C H 4}\right)$, and other light gases $\left(Y_{\text {other }}\right)$. Because the experimental conditions were different from the proximate analysis conditions, the mass fraction of volatile matter is noted as $Y_{V Y}$. This $Y_{V Y}$ is composed of light gases $Y_{L G}$ and $\operatorname{tar} Y_{T a r}$, defined by

$$
Y_{V Y}=Y_{L G}+Y_{T a r}
$$

$\mathrm{Y}_{\mathrm{LG}}$ is constructed from the light gas components as follows:

$$
Y_{L G}=Y_{H 2 O}+Y_{C O 2}+Y_{C O}+Y_{C H 4}+Y_{\text {Others }}
$$

Due to the difference in the experimental conditions, the yield of volatile matter $Y_{V Y}$ is different from the mass fraction of volatile matter $Y_{V M}$ that was measured in the proximate analysis. The volatile enhancement was introduced by Mill [4] as

$$
V_{E}=\frac{Y_{V Y}}{Y_{V M}}
$$




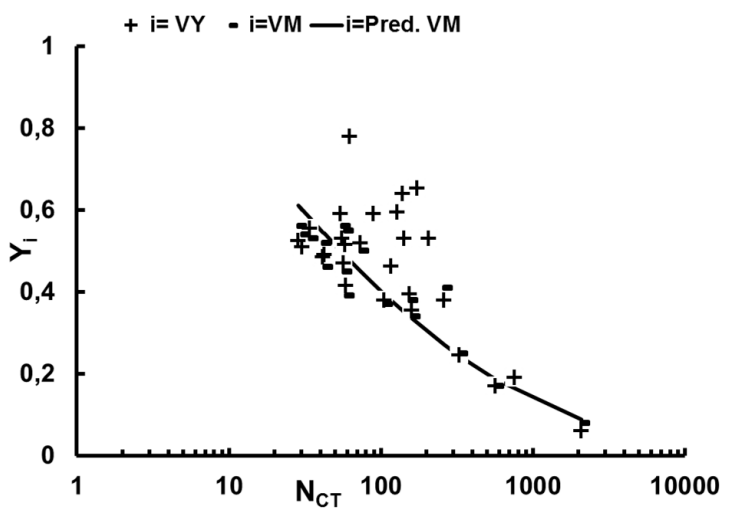

Figure 5 Correlation of volatile yield $Y_{V Y}$ and volatile matter mass fraction in proximate analysis $Y_{V M}$ with the coal type number $N_{C T}$ and predicted volatile matter mass fraction (Pred. VM) using Eqs. 10 and 11. Measured data from $\mathrm{Xu}$ and Tomita [6].
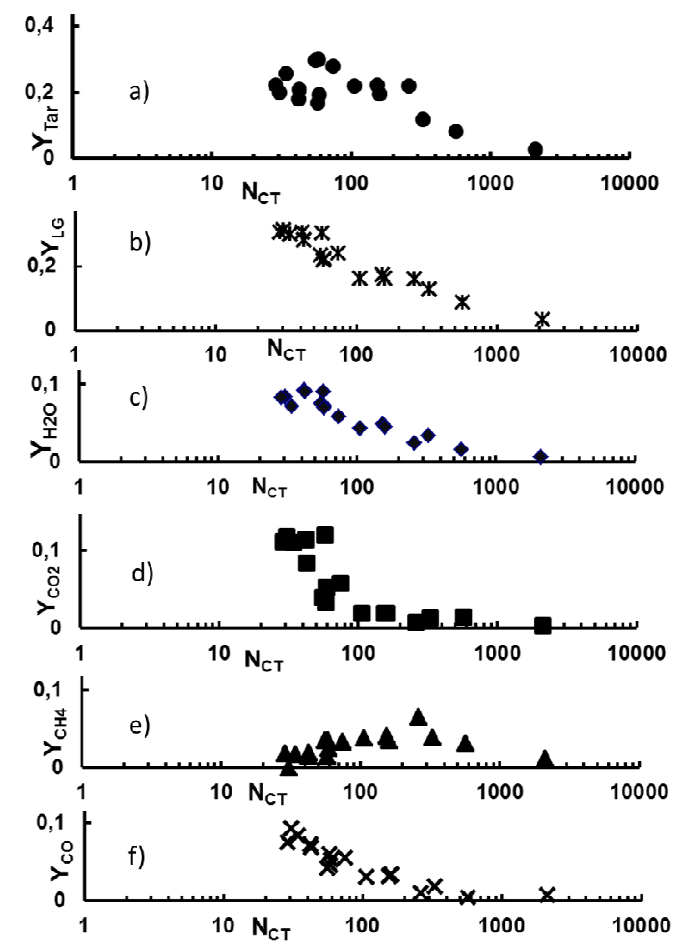

Figure 6 Correlations of light gas $Y_{L G}, Y_{t a r}$, and components $Y_{\mathrm{H} 2 \mathrm{O}}, Y_{\mathrm{CO} 2}, Y_{\mathrm{CH} 4}$, and $Y_{C O}$ yield with coal type number $N_{C T}$. Measured data from $\mathrm{Xu}$ and Tomita [6]. 
$Y_{V Y}$ was correlated to the $\% Y_{C}$ of the coal ultimate analysis by $\mathrm{Xu}$ and Tomita [6]. In the present work, the coal type number $N_{C T}$ is used to show the effect of the coal type. The present correlation is shown in Figure 5. This correlation reveals a trend similar to the $Y_{V M}$ correlation. The similarity in the trend is one of the strengths of using the $N_{C T}$ coal type number rather than using $\% Y_{C}$. The tar and light gas mass fractions also have a trend similar to the $Y_{V M}$ correlation, as shown in Figure 6 frames a) and b). The mass fractions of each component of the light gases were also plotted against $N_{C T}$, as shown in Figure 6 frames c) to f). Notably, there is a behavior trend of the mass fraction of each component similar to $Y_{V M}$ against $N_{C T}$, except for the $\mathrm{CH}_{4}$ component. The $Y_{C H 4}$ plot, as observed in Figure 6 frame e), forms a maximum value.

\subsubsection{Effects of Temperature and Heating Rate}

The effect of temperature on the pyrolysis behaviors is well understood. Coal or biomass pyrolysis is a thermal decomposition process. This process has a strong temperature dependence that is controlled by the chemical kinetics. The decomposition products of coal and biomass are solid char, tar, and light gases. The light gases consist of the gas components stated in Eq. (16). The kinetic mechanism of the coal or biomass pyrolysis with very small particles is commonly modeled as a simple mechanism that leads to the absence of the secondary reaction of the tar. This mechanism also does not include the distribution of activation energy. Moreover, using the detail mechanism for constructing the empirical correlation of volatile yield with temperature and heating rate is not required.

A first order and simple kinetic expression of the coal or biomass was used to build the correlations of $Y_{V Y}$ and $Y_{V M}$ to temperature and heating rate. The heating rate $\beta$ is proportional to the temperature gradient along the time of sample $\partial T / \partial t$. The pyrolysis conditions are most likely different from the proximate analysis conditions. The standard temperature $T_{S}$, pressure $P_{S}$ and heating rate are $900^{\circ} \mathrm{C}, 1 \mathrm{~atm}$ and $\beta_{S}$, respectively. The resulting mass fraction of the released volatiles is $Y_{V M}$. If a pyrolysis process is conducted at temperature $T$, heating rate $\beta$ and pressure similar to the proximate analysis, the mass fraction of the released volatiles is stated as $Y_{V Y}$. The ratio between the released volatiles $Y_{V Y}$ for a pyrolysis process under a certain condition to the released volatiles under standard conditions $Y_{V M}$ is proposed as follows

$$
\frac{Y_{V Y}(T)}{Y_{V M}\left(T_{S}\right)}=e^{f_{4}\left(\frac{\beta}{\beta_{s}}, \frac{T}{T_{S}}\right)}
$$


Eq. (18) has the same definition as volatile enhancement Eq. (17). The volatile enhancement exists due to the temperature and heating rate effects.

References [14]-[19] report the measurement of released volatile mass fraction $Y_{V Y}$. The measurement conditions varied the heating rate, temperature and residence time. Each of them used different types of coals and biomass. A summary of the experimental conditions is listed in Table 1. These data were used in this study to explore the correlation that is defined by Eq. (18).

The correlation of $V_{E}$ for different coal and biomass types with $T / T_{S}$ was generated using the measured data from the aforementioned references. The results are shown in Figure 7. The data show that a single correlation for $Y_{V Y} / Y_{V M}$ with $T / T_{S}$ can be drawn that covers all types from biomass to bituminous coal, heating rates from 0.4 to $1500^{\circ} \mathrm{C} / \mathrm{s}$, and residence time from 7 to $500 \mathrm{~s}$. This finding indicates a unique correlation between volatile enhancement $V_{E}$ and temperature ratio $T / T_{S}$. The effect of the heating rate on $V_{E}$ is shown to be minor. Oh [19] has shown that the effect of the heating rate on $Y_{V Y}$ is less than a $4 \%$ increase when increasing the heating rate 10 times. A similar result was shown by Jamil, et al. [20], who stated that an increase in the heating rate from 0.5 to $1000^{\circ} \mathrm{C} / \mathrm{s}$ gives an increase of only $1 \%$ in the $\% Y_{V Y}$.

Volatile enhancement $V_{E}$ is concluded to be a significant function of temperature ratio $T / T_{S}$. Eq. (18) is simplified into

$$
\frac{Y_{V Y}(T)}{Y_{V M}\left(T_{S}\right)}=e^{f_{5}\left(\frac{T}{T_{S}}\right)}
$$

Table 1 The experimental conditions for the volatile matter mass fractions $Y_{V Y}$ at various temperature levels from references [11,19,21-24].

\begin{tabular}{|c|c|c|c|c|c|c|}
\hline $\begin{array}{c}\text { Literature } \\
\text { Pressure }\end{array}$ & $\begin{array}{c}{[11]} \\
1 \text { atm }\end{array}$ & $\begin{array}{c}{[19]} \\
1 \text { atm }\end{array}$ & $\begin{array}{c}{[21]} \\
1 \text { atm }\end{array}$ & $\begin{array}{c}{[22]} \\
1 \text { atm }\end{array}$ & $\begin{array}{c}{[23]} \\
1 \text { atm }\end{array}$ & $\begin{array}{c}{[24]} \\
1 \text { atm }\end{array}$ \\
\hline Heating rate & $\begin{array}{c}500-1500 \\
{ }^{\circ} \mathrm{K} / \mathrm{s}\end{array}$ & $1000^{\circ} \mathrm{C} / \mathrm{s}$ & $\begin{array}{c}30-300 \\
{ }^{\circ} \mathrm{K} / \mathrm{s}\end{array}$ & $1000^{\circ} \mathrm{C} / \mathrm{s}$ & $23^{\circ} \mathrm{C} / \mathrm{s}$ & $0.42^{\circ} \mathrm{K} / \mathrm{s}$ \\
\hline $\begin{array}{l}\text { Temperature } \\
\text { range }\end{array}$ & $\begin{array}{c}800-1600 \\
{ }^{\circ} \mathrm{C}\end{array}$ & $\begin{array}{c}200-1000 \\
{ }^{\circ} \mathrm{C}\end{array}$ & $\begin{array}{c}500- \\
1000^{\circ} \mathrm{C}\end{array}$ & $\begin{array}{c}598-1057 \\
{ }^{\circ} \mathrm{C}\end{array}$ & $\begin{array}{c}650- \\
800^{\circ} \mathrm{C}\end{array}$ & $\begin{array}{c}650- \\
1025^{\circ} \mathrm{C}\end{array}$ \\
\hline $\begin{array}{l}\text { Resicence } \\
\text { time }\end{array}$ & $140 \mathrm{~s}$ & $7 \mathrm{~s}$ & $30 \mathrm{~s}$ & & $300 \mathrm{~s}$ & $500 \mathrm{~s}$ \\
\hline $\begin{array}{c}\text { Coal or } \\
\text { Biomass } \\
\text { Type }\end{array}$ & $\begin{array}{c}\text { Lignite } \\
\text { PSOC-246 }\end{array}$ & $\begin{array}{l}\text { Pittsburgh } \\
\text { No. } 8\end{array}$ & & $\begin{array}{l}\text { Illinois } \\
\text { No. } 6\end{array}$ & $\begin{array}{l}\text { Lignite } \\
\text { Texas }\end{array}$ & $\begin{array}{l}\text { Wood } \\
\text { Chips }\end{array}$ \\
\hline
\end{tabular}

Function $f_{5}$ is fitted using the data from the various sources. The best fitted model generates function $f_{5}\left(T / T_{s}\right)$ as follows: 


$$
\begin{aligned}
f_{5}\left(\frac{T}{T_{S}}\right)= & 3.87\left(\frac{T}{T_{S}}\right)^{5}-28.28\left(\frac{T}{T_{S}}\right)^{4}+80.87\left(\frac{T}{T_{S}}\right)^{3}- \\
& 112.8\left(\frac{T}{T_{S}}\right)^{2}+77.07\left(\frac{T}{T_{S}}\right)-20.6
\end{aligned}
$$

This work proves that the volatile enhancement is a function of the temperature ratio only.

Stubington and Sasongko's [25] conclusion for coal pyrolysis performances at a heating rate from 2 to $150 \mathrm{~K} / \mathrm{s}$ and coal particle sizes from 2 to $20 \mathrm{~mm}$ is that the volatile yield under fluidized bed combustor conditions is approximately the same as the volatile matter in the proximate analysis result. This infers that the present correlation Eq. (19) could be used to estimate the volatile yield for coal sizes up to $20 \mathrm{~mm}$.

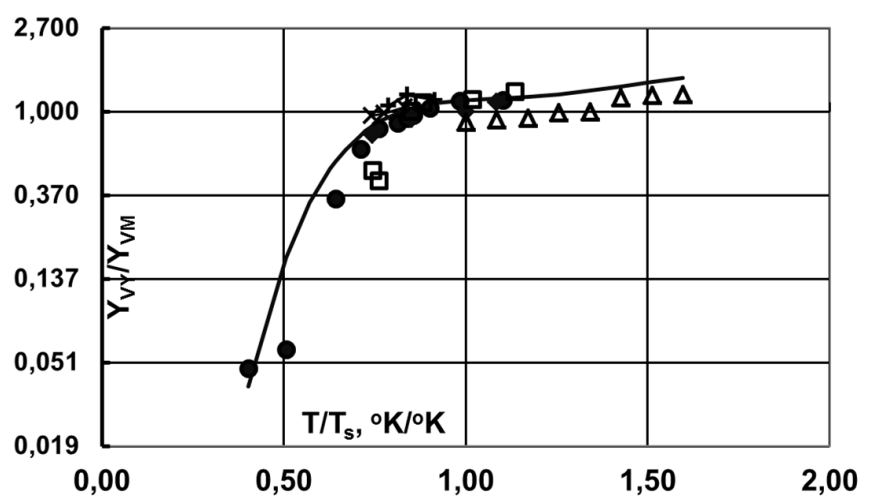

Figure 7 Correlation of $Y_{V Y} / Y_{V M}$ at various temperatures $T / T_{S}$, data from [11,19,21-24], and the line fitted model Eqs. (19) and (20).

\subsubsection{General Empirical Correlation}

A general correlation for predicting the pyrolysis performance in terms of volatile yield $Y_{V Y}$ for a broad range of coal and biomass types as a function of temperature $T$ and coal type number was successfully developed and constructed using data available in the literature. This correlation is stated as follows:

$$
Y_{V Y}\left(N_{C T}, T\right)=e^{f_{5}\left(\frac{T}{T_{S}}\right)} e^{f_{2}\left(N_{C T}\right)}
$$


The effect of the coal or biomass type is stated by exponential function $f_{2}$, which is solely a function of $N_{C T}$. This function is expressed by Eq. (11). The effect of temperature is described by exponential function $f_{5}$. The $f_{5}$ function is a function of the temperature ratio $T / T_{s}$ observed in Eq. (20). The effect of heating itself is minor; on the whole, it contributes insignificantly to the $f_{5}$ function.

The mass fraction of a volatile component $y_{i}$ is defined as

$$
y_{i}=\frac{Y_{H 2 O}}{Y_{V Y}}
$$

where the $i$-component is $\mathrm{H}_{2} \mathrm{O}, \mathrm{CO}_{2}, \mathrm{CO}, \mathrm{H}_{2}, \mathrm{CH}_{4}$, tar and others. The summation for all mass fractions should be equal to one. This is a constraint factor for $y_{i}$. The correlation for the mass yield of each volatile component according to temperature $T$ and $N_{C T}$ is further formulated as follows:

$$
Y_{i}=y_{i} e^{f_{5}\left(\frac{T}{T_{S}}\right)} e^{f_{2}\left(N_{C T}\right)}
$$

Because the effects of all of the variables are grouped with $Y_{V Y}$ in Eq. (21), the performances of $y_{\mathrm{i}}$ can be expected to be constants; if they are not, there will be some interaction effects between components. If one component increases its yield with $N_{C T}$, there will be at least one component that has a decreased yield. To determine how these $y_{i}$ 's behave, the measured data for the component yields of the light gases and tar from Xu and Tomita [6] were used. The plots of $y_{i}$ versus $N_{C T}$ are given in Figure 8. The mass fraction for the total light gases is constant as observed in Figure 8 frame b), which is similar for the tars as well, as shown in Figure 8a. The mass fractions for the $\mathrm{H}_{2} \mathrm{O}$ and $\mathrm{CO}_{2}$ components can be stated to be constant. These are shown by Figure 8 frame c) and d). The mass fraction for $\mathrm{CO}$ increases with $N_{C T}$. To counter that, the mass fraction for $\mathrm{CH}_{4}$ is shown to decrease with $N_{C T}$.

Eq. (23) is very valuable in predicting the light gas and tar composition. The only values that have not been modeled are the $y_{i}$ values. In this work, it is shown how each $y_{\mathrm{i}}$ behaves with $N_{C T}$. The mass fractions of the light gases and tar show a scattered behavior with $N_{C T}$. A similar correlation trend exists for the $\mathrm{H}_{2} \mathrm{O}$ and $\mathrm{CO}_{2}$ gases. However, the correlations between $y_{C O}$ and $y_{C H 4}$ with $N_{C T}$ are shown to decrease consistently. Interestingly, the summation between $y_{C O}$ and $y_{C H 4}$ is shown to be constant along the $N_{C T}$ axis. The expectation that the values should be constant is valid for all $y$ 's except for the individual $y_{C O}$ and $y_{C H 4}$. The function of $y_{i}$ in Eq. (23) can be determined if there are more comprehensive data available on component yields in the released volatiles. 

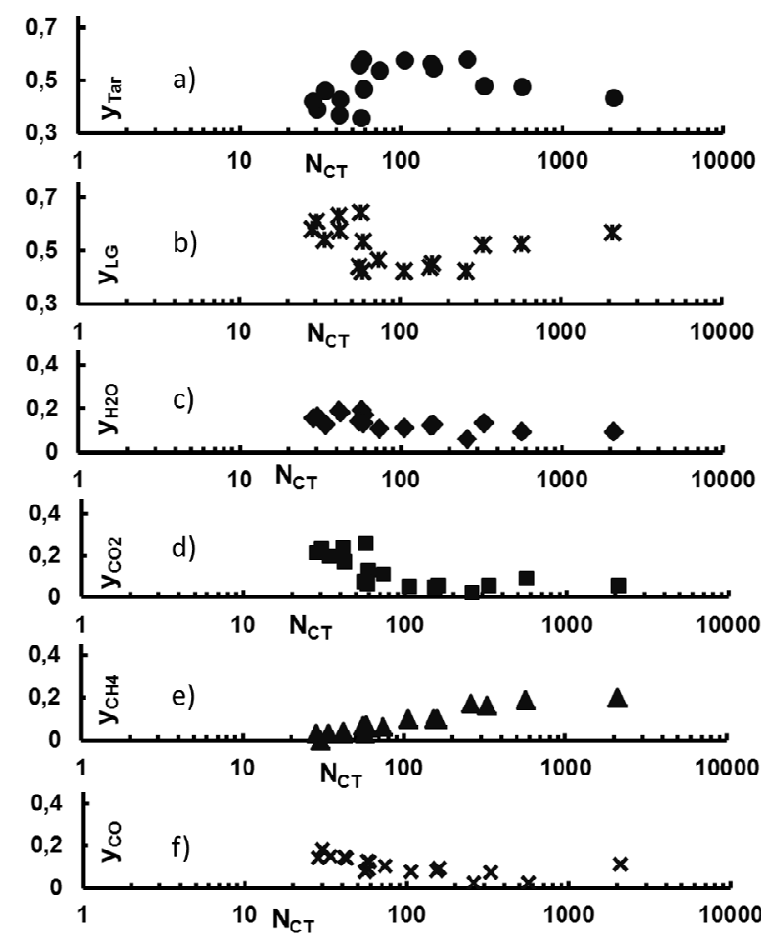

Figure 8 Generated correlations of mass fractions of light gas $y_{L G}$, tar $y_{\text {Tar }}, y_{H 2 O}$, $y_{\mathrm{CO} 2}, y_{\mathrm{CH} 4}$ and $y_{\mathrm{CO}}$ in the total volatile matter yield when compared with $N_{C T}$. Measured data from $\mathrm{Xu}$ and Tomita [6].

\section{Conclusions}

A coal or biomass type number has been developed successfully. This parameter uses the mass fractions of carbon, hydrogen and oxygen $\left(Y_{C}, Y_{H}\right.$ and $Y_{O}$ ) that were obtained from ultimate analysis data to give a numeric value observed as $N_{C T}=\left(Y_{C} / Y_{H}\right)\left(Y_{C} / Y_{O}\right)$. The value of this number is unique for each type of coal or biomass. The mass fractions of the volatile matter have a unique exponential correlation to the polynomial function $\ln \left(N_{C T}\right)$. The heating values of a coal or biomass type also have a unique correlation to the coal type number and ash mass fraction.

With this unique correlation to the mass fraction of the volatile matter, the temperature effect and heating rate become quantifiable and result in a general correlation that allows the prediction of the pyrolysis performances in terms of the volatile yield $\left(Y_{V Y}\right)$ for a broad range of coal and biomass types. This correlation is generated by multiplying the temperature and coal type functions. 
The effect of self-heating is minor and becomes part of the temperature function.

The resulting general correlation for the mass yield of a component in the volatile matter is characterized by the total mass yield correlation and a component weight factor correlation. The weight factor equals the mass fraction of the component in the released volatile matter. The weight factors for some of the components are constant for the variation of $N_{C T}$, but not for others. A constraint for this factor is that the summation of the mass fractions must be equal to one. For future work, it is recommended to formulate each component yield function from more comprehensive experimental data to predict pyrolysis performances.

\section{References}

[1] Niksaa, S., Liua, G.S. \& Hurtb, R.H., Coal Conversion Submodels for Design Applications at Elevated Pressures. Part I. Devolatilization and Char Oxidation, Progress in Energy and Combustion Science, 29, pp. 425-477, 2003.

[2] Mill, C.J., Pyrolysis of Fine Coal Particles at High Heating Rate and Pressure, Ph.D. Thesis, University of New South Wales, 2000.

[3] Genetti, D.B., An Advanced Model of Coal Devolatilization Based on Chemical Structure, M.Sc. Thesis, Brigham Young University, Provo, Utah, United States, 1999.

[4] Schlosberg, R.H., Chemistry of Coal Conversion, Plenum Press, New York, 1985.

[5] Solomon, P.R., Hamblen, D.G., Carangelo, R.M., Serio, M.A. \& Deshpande, G.V., General Model for Coal Devolatilazation, Energy and Fuels, 2, pp. 405-422, 1988.

[6] Xu, W. \& Tomita, A., Effect of Coal Type on the Flash Pyrolysis of Various Coals, Fuel, 66, 627-631, 1987.

[7] Lee, C.W., Scaroni, A.W. \& Jenkins, R.G., Effect of Pressure on the Devolatilization and Swelling Behaviour of a Softening Coal during Rapid Heating, Fuel, 70, pp. 957-965, 1991.

[8] Fatemi, M., Effect of Pressure on Pyrolysis of a Sub-Bituminous Coal in an Entrained-Flow Reactor, Am. Chem. Soc. Div. Fuel Chem., 32, pp. 117-124, 1987.

[9] Yeasmin, H., Mathews, J.F. \& Ouyang, S., Rapid Pyrolysis of Yallourn Brown Coal at High Pressures and Temperatures, Fuel, 78, pp. 11-24, 1999.

[10] Zeng, D., Effect of Pressure on Coal Pyrolysis at High Heating Rates and Char Combustion, Ph.D Thesis, Brigham Young University, Provo, Utah, United States, 2005. 
[11] Tamhankar, S.S., Sears, J.T. \& Wen, C.Y., Coal Pyrolysis at High Temperatures and Pressures, Symposium on Coal Gasification, 1, Las Vegas, 1982, www.anl.gov/PCS/acsfuel/preprint archive/27_1_LAS Vegas_03-82.htm, October 17, 2011

[12] Berkowitz, N., The Chemistry of Coal, Elsevier, Amsterdam, 1985.

[13] Lee, S.H., Kim, D.S. \& Lee, D.H., Particle Size Reduction of Anthracite Coals during Devolatilization In A Thermobalance Reactor, Fuel, 81(13), pp. 1633-1639, 2002.

[14] Qi, Y., Li, W., Chen, H. \& Li, B., Desulfurization of Coal Through Pyrolysis in A Fluidized-Bed Reactor under Nitrogen and $0.6 \% \mathrm{O}_{2}-\mathrm{N}_{2}$ Atmosphere, Fuel, 83(6), pp. 705-712, 2004.

[15] Tillman, D.A., Biomass Cofiring: The Technology, The Experience, The Combustion Consequences, Biomass and Bioenergy, 19(6), pp. 365-384, 2000.

[16] Ahn, D.H., Gibbs, B.M., Ko, K.H. \& Kim, J.J., Gasification Kinetics of an Indonesian Sub-Bituminous Coal-Char with $\mathrm{CO}_{2}$ at Elevated Pressure, Fuel, 80(11), pp. 1651-1658, 2001.

[17] Parikh, J., Channiwala, S.A. \& Ghosal, G.K., A Correlation for Calculating HHV from Proximate Analysis of Solid Fuels, Fuel, 84, pp. 487-494, 2005.

[18] van Krevelen, D.W., Coal, Coal Science and Technology, 3, Elsevier, Amsterdam, 1981.

[19] Oh, M.S., Softening Coal Pyrolysis, D.Sc. Thesis, Massachusetts Institute of Technology, Cambridge, Massachusetts, United States, 1985.

[20] Jamil, K., Hayashi, J. \& Li, C.Z., Pyrolysis of a Victorian Brown Coal in Helium and $\mathrm{CO}_{2}$ Atmosphere, Journal of Energy \& Environment, 4, pp. 83-96, 2005.

[21] Kawamura, T., Hashimoto, S., Sakawa, M., Kozuro, H., Iida, H. \& Okuhara, T., Study on Coal Flash Pyrolysis, Nippon Steel Technical Report, 47, 1993.

[22] Rose, G.R. \& Zabransky, R.F., The Preparation of Pyrolysis of $O$ and $C$ Benzylated Illinois No. 6 Coal, Symposium on Devolatilization of Carbonaceous Materials, 29(2), St. Louis, 1984.

[23] Jih, J.S., Determination of Pyrolysis Kinetic Parameters of San Miguel (Texas) Lignite, M.Sc. Thesis, Texas Tech University, 1982.

[24] Blasi, D., Signorelli, G., Russo, D.C. \& Rea, G., Product Distribution of Woods and Agricultural Residues, Industrial Engineering Chemistry Research, 38, pp. 2216-2224, 1999.

[25] Stubington, J.F. \& Sasongko, D., On the Heating Rate and Volatile Yield for Coal Particles Injected into Fluidized Bed Combustors, Fuel, 77, pp. 1021-1025, 1998. 